lasting about five months. She suffered frequently from pelvic pain and occasional leucorrhoe till the present illness. Her last menstrual periods were July 12th, July 22nd, and August 12th of last year, since when she had intermittent brownish discharge and dull, aching pelvic pain. She suspected that she was pregnant. On Sept. 27 th, about 8 A.M., she was suddenly seized with severe pain in the left pelvis and hypogastrium and sent for me. Examination of the breasts bore out her suspicion of pregnancy and per vaginam the true nature of the condition was diagnosed by the feeling of an hæmatocele filling the left pelvis. After rallying from this attack she, abont 1 P.M., showed signs of collapse from internal hæmorrhage and consented to immediate operation. On opening the abdomen a placenta and two foetuses were found separately among a huge mass of blood clot which was rapidly removed and the ruptured tube brought up to the wound, its ends tied in one grasp of the ligature, then cut away and the stump returned to the pelvis. The peritoneal cavity was flushed out with hot saline solution, at least a quart being left in when the wound was closed. The patient was back in bed again within 20 minutes of the commencement of the anæsthetic and made an uninterrupted recovery. She remains, six months after the operation, in excellent health. In our anxiety for the welfare of the patient we unfortanately allowed the placenta to be thrown away in the process of tidying ap, thus leaving the specimen incomplete but as it is it may be considered worthy of reproduction. One foetus may be seen to be still enveloped in a separate amniotic sac.

I am indebted to Mr. H. Allan for his assistance at the operation and to Mr. F. E. Daniel for photographing my gelatin preparation of the specimen.

Barrow-in-Furness.

\section{A CASE OF SUPPURATING HYDATID OF THE GALL- BLADDER ; OPERATION ; RECOVERY.}

By ARThur G. L. READE,

SENIOR HOUSE SURGEON TO THE RADCLIFFE INFIRMARY, OXFORD.

A MAN, aged 31 years, a labourer, was admitted to the Radcliffe Infirmary and County Hospital, Oxford, under the care of Dr. W. T. Brooks, on Sept. 24th, 1906, complaining of acute abdominal pain. He had always been a healthy man until August 22nd, when he was in this hospital under the care of Mr. H. P. Symonds suffering from biliary colic. At that time his stools were white and his urine was dark brown; the conjunctivæ were yellow. There was nothing to be made out in the abdomen and, as he refused operation, in a fortnight's time he was discharged, as by that time he had recovered. He remained well until Sept. 22nd, when he was suddenly seized with sharp pain in the stomach and back which doubled him up he vomited several times and sweated with pain. This pain had been continuous and the vomiting was so persistent that he could retain no food. The bowels were opened on the $23 \mathrm{rd}$, since which date he had began to get yellow. He had had no sleep for the last two nights on account of the pain; his urine was very dark in colour. He had never been abroad and there was nothing of importance in the family history. His condition on admission was as follows. The patient lay on his back with his knees slightly drawn up, he had an anxious expression, and his respirations were hurried. His face had a yellow tinge and the cheeks were red. His temperature was $103 \cdot 8^{\circ} \mathrm{F}$., his pulse was 120 , and his respirations were 28 ; the conjunctivæ were markedly yellow and the tongue was furred. On examining the abdomen it was noticed that the skin was yellow and movement was very slight. There was marked fulness in the epigastrium. On palpation there was definite resistance in the epigastrium towards the right side and the abdomen was exquisitely tender above the umbilicus. Nothing was to be made out in the lower part of the abdomen. On percussion resonance over the upper part of the abdomen was impaired; there was liver dulness to the fifth rib. The patient had a bad night. only sleeping when under the influence of morphine; on the next morning the temperature fell to $98^{\circ}$, but the pulse remained 120 , and a blood count showed marked leucocytosis $(19,000)$. The patient was transferred to $\mathrm{Mr}$. Symonds's care and at 3.30 on that day (the 25th) was operated on. An incision about four inches long was made to the right of the mid-line over the region of the gall-bladder and on opening the peritoneum a little free fluid escaped. The gall-bladder was found to be distended and on opening it, the rest of the peritoneum having been packed off as far as possible, a considerable quantity of pus escaped mixed with a large number of hydatid cysts. On exploring with the finger another cyst apparently in the liver substance was opened, which also contained pus and daughter cysts. The walls of these two cavities, which had now been made one, were sutured to the abdominal wall and a drain was put in. The rest of the incision was sutured. On the next day the patient was much better and daily continued to improve, though a very large quantity of bile escaped. Three weeks later the patient was again taken to the theatre and a pursestring suture was put round the neck of the cyst, tying in a Paul's tube, which drained the bile by a piece of indiarubber tubing attached to the tube away from the wound. Ten days later this was removed and the edges of the wound were cauterised. Under this treatment the biliary fistula closed about five weeks later, and on Dec. 29th the patient was discharged cured. He had been seen since his discharge and was keeping quite well.

Remarks by Mr. READE. - There are two interesting points in this case: first that the patient had never been abroad, nor was there any clue as to how he contracted hydatid disease ; and secondly, that the daughter cysts gave rise to symptoms exactly like biliary colic followed by suppurative cholecystitis, of which nature the case was considered to be until operation. While very common in the liver the literature shows that hydatid disease affecting the gall-bladder is extremely rare. I find notes of eight acses, two of which occurred in this country. Mr. E. T. Burton reports a case under Mr. H. G. Barling's care in the Birmingham Medical Heview of October, 1897. The patient's symptoms were very similar to those in the case here recorded. The duration of the acute illness was ten days and though he was admitted with a view to operation he was too ill to stand it and died three days after admission. Post mortem in addition to the cyst in the wall of the gallbladder several daughter cysts were found in the bladder itself. Mr. Frederick Page reports a case in THE LANCET of April 9 th, 1898, p. 995. This patient suffered from "bilious attacks"-i.e., epigastric pain and vomiting for five years; a tumour was felt over the region of the gall-bladder, which when explored proved to be a single hydatid cyst with no daughter cysts ; this was removed and the patient recovered.

I am indebted to Dr. Brooks and to Mr. Symonds for permission to publish this case, but my description of $\mathrm{Mr}$. Symonds's operation has not had the great advantage of his corrections.

\section{A CASE OF DUPUYTREN'S CONTRACTION TREATED WITH FIBROLYSIN.}

BY W. Duncan Lawrie, M.D. Edin., F.R.C.S. Edin., HONORARY SURGEON TO THE BIRMIYGHAM CRIPPIED CHILDREN'S UNION,

THE following case may perhaps claim to be of sufficient interest to be recorded in THE LANCET.

The patient, a man, aged 42 years, came under observation in November, 1906. The three illustrations here given speak

FIG. 1.

FIG. 2.

FIG. 3.

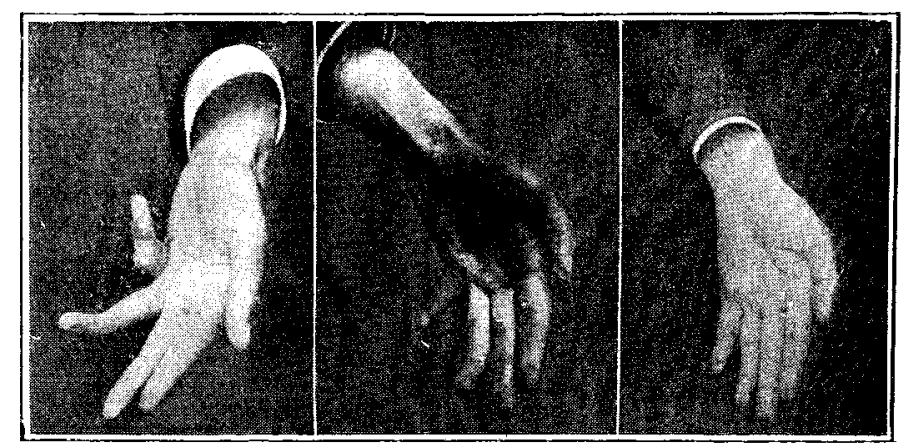

for themselves and thus obviate the necessity for a detailed description of the case. Fig. 1 shows the condition at the commencement of treatment. The patient could only come for treatment at the week ends and accordingly the contents of one of Merck's ampullæ containing $2 \cdot 3$ cabic centimetres of fibrolysin were injected on Saturday, Sunday, and Monday 